\title{
COMPARISON OF COMMERCIALLY AVAILABLE NICKEL TITANIUM PREFORMED ARCHWIRES WITH THE COMMON ARCHFORM FOUND IN INDIAN POPULATION - AN EXPERIMENTAL STUDY
}

\author{
Dr. Pankaj Akhare ${ }^{1}$, Dr. Mohini Dharmadhikari ${ }^{2}$, Dr. Harish Atram ${ }^{3}$, Pratik Jaltare ${ }^{4}$, Dr. Kshitij Sabley ${ }^{4}$, \\ Dr. Akanksha Kumar ${ }^{4}$ \\ 1- Professor \& Guide, 2- Postgraduate Student, 3- Reader, 4- Senior Lecturer, Department of Orthodontics and \\ Dentofacial Orthopaedics, Swargiya Dadasaheb Kalmegh Smruti Dental College and Hospital, Nagpur
}

\section{ABSTRACT}

Objective: To evaluate most suitable preformed Nickel Titanium Archwires for ovoid archform which is commonly observed in the population. Material and methods: Sixty casts of mandibular arches with ovoid arch form were included of the patients visiting Department of Orthodontics. The buccal and incisal edges of all teeth on the cast were marked by HB pencil on the mandibular study models and were transferred on a sheet of paper. Nickel Titanium archwires of ovoid form of four different companies were compared by matching them with the arch forms obtained from the patients. Results: There is significant difference in the preformed archwires obtained from 4 different companies when compared to the ovoid archform. The archwires used are wider than the normal arch form observed. Conclusion: Variation in available preformed arch wires does not entirely cover the range of diversity of the common dental arch form of our population.

KEYWORDS: NiTi, Archform, Retention.

\section{INTRODUCTION}

One of the most important part of orthodontic treatment depends on preserving the patient's pretreatment arch form and arch size during and at the end of treatment. ${ }^{1-3}$ According to Riedel's theorems of retention- "Arch form, particularly in the mandibular arch, cannot be permanently altered by appliance therapy." "Though arch width and arch form are interdependent parameters, the dimensional changes of arch might affect arch form as well. ${ }^{5}$ Although different classifications of arch - form have been suggested, three main arch forms (ovoid, tapered, square) are commonly used by the clinicians. ${ }^{6}$ Longitudinal studies have shown high probability of relapse after increasing arch width especially in the mandibular canine region. ${ }^{1}$

When the Edgewise technique was first introduced in the 1920s, bending the arch wires in order to match the dental arch was an important part of orthodontic treatment and dental casts were used in order to form arch wires. ${ }^{7}$ 
Since the introduction of nickel-titanium wires, preformed types of these wires have been widely used, particularly in the initial phases of orthodontic treatment. ${ }^{1}$ This type of arch wire has become popular for it is believed to provide "greater efficiency" during this stage of treatment. Because of the metallurgic composition of these arch wires, the clinician is unable to adjust their form or size to a given patient. ${ }^{8}$ Some orthodontists neglect the size of preformed nickel-titanium wires, since they believe the original arch size and arch shape will return back after using stainless steel arch wires with appropriate size and shape. This method is not recommended because it causes round tripping movement of the teeth during treatment and increases the subsequent side effects. ${ }^{1,8}$

Dental arches vary in different races and populations. Therefore, arch wires should be selected according to the related population's arch size and arch shape. Because most of the available arch wires in India are designed according to normal dental arches of European and American population, this study was undertaken to compare the commercially available preformed nickeltitanium arch wires with the Indian Angle class I malocclusion dental arches and introduce the highest correlated arch wires with Indian dental arch size and shape.

\section{MATERIALS AND METHOD}

Our study samples were 60 orthodontically untreated patients. They were selected through convenient sampling among the patients visiting the department of orthodontics and dentofacial orthopaedics, SDKS Dental College and Hospital, Nagpur.

The inclusion criteria were having dental Class I, normal overjet (1-2 $\mathrm{mm})$ and overbite $(2-3 \mathrm{~mm})$, aligned teeth with minimum crowding and symmetric lower dental arch (checked with a transparent ruled grid). Dental Class I was selected based on Class I canine and molar relationships. Subjects with the history of orthodontic treatment or posterior cross bite were excluded from the study. None of the selected cases had supernumerary or missing teeth or anterior teeth restorations.

Step 1: Buccal and incisal edges of lower teeth on the plaster model are marked with a HB pencil. (Fig. 1).

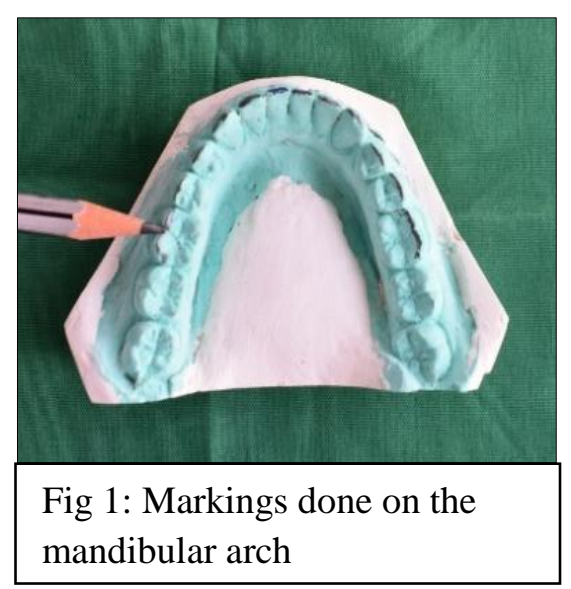

Step 2: A plain sheet of paper $(6 \mathrm{~cm} \times 10 \mathrm{~cm})$ is kept over the occlusal surface of lower cast and stabilized from posterior region with thumb and index finger.

Step 3: Index finger of other hand is moved over the sheet of paper to facilitate transfer of the pencil marks on the sheet. (Fig. 2)

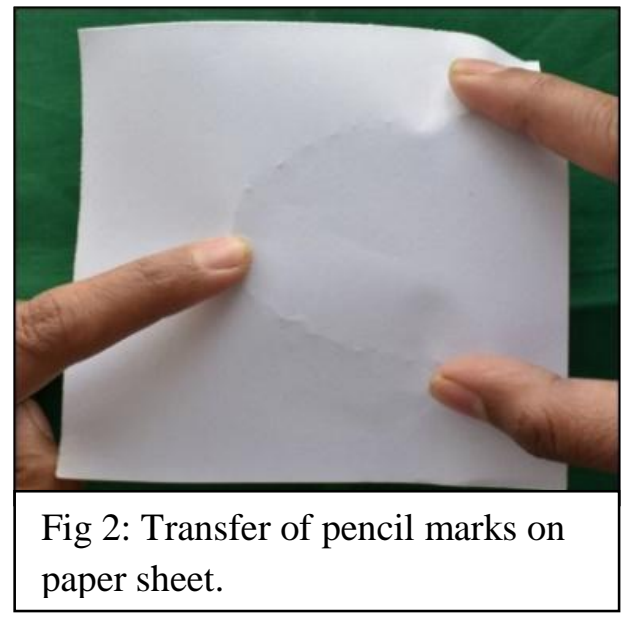

Step 4: Pencil marks get transferred on the under surface of sheet of paper and arch form is obtained. Mark the midline. (Fig. 3) 


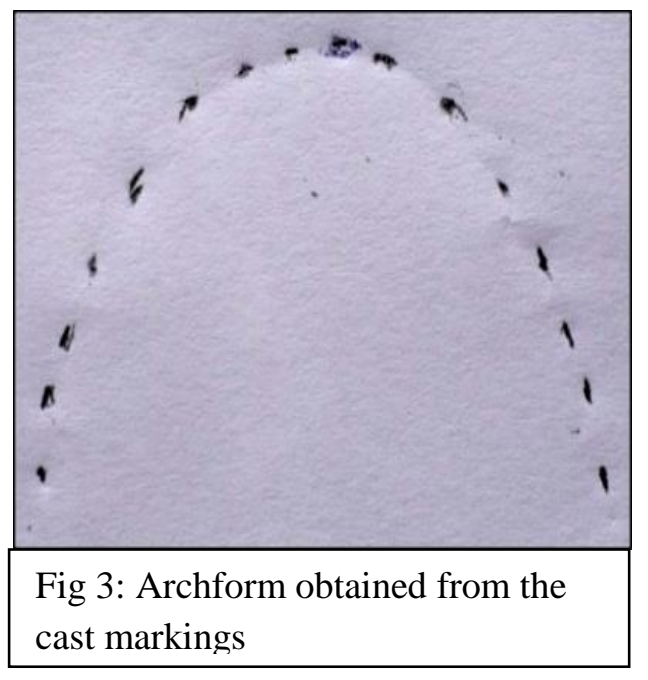

Step 5: The arch form obtained can be transferred to graph paper. Place this paper on tracing table and get the markings on graph paper. Draw a curve out of the markings. (Fig. 4)

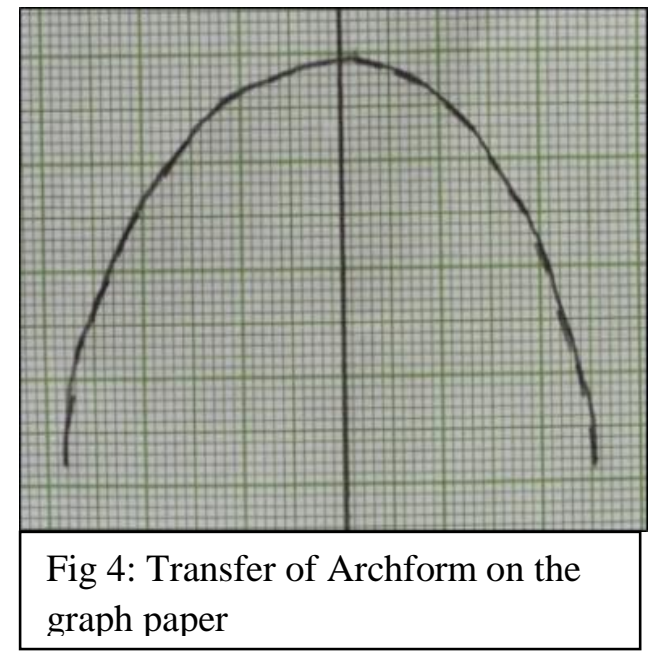

Step 6: The four commercially-available brands of preformed nickel-titanium arch wires - $\mathrm{G} \& \mathrm{H}$ Orthodontics, JJ Orthodontics, DC Orthodontics and d-tech Orthodontics are taken. (Fig. 5)

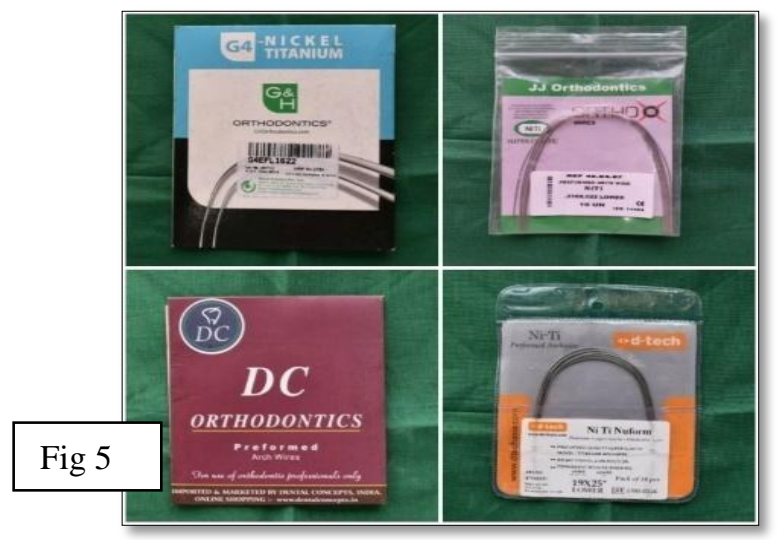

The commercially-available brands are then compared to the archform drawn on the graph paper in the intercanine and the intermolar region and the difference is noted in mm. (Fig. 6)

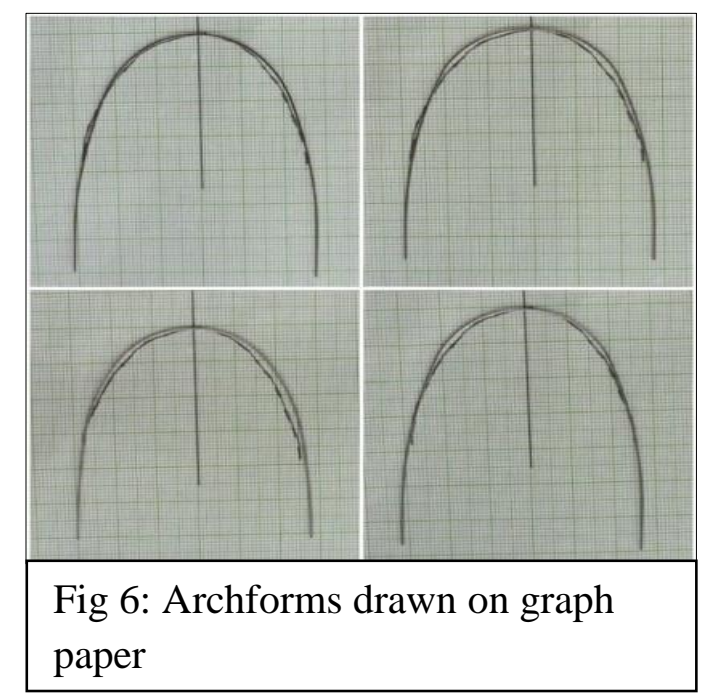

\section{STATISTICAL ANALYSIS}

Comparison of difference between intercanine and intermolar width between arch form with four different brands of archwires was done using descriptive statistics. The variation between the groups and within the groups is done using Oneway ANOVA. Comparison between archwires of different brands is done using Multiple comparison: Tukey test.

\section{RESULTS}

In the present study, the comparison of the intercanine width and intermolar width between the obtained arch forms from the mandibular dental casts obtained and the archwires of four different brands (G \& H Orthodontics, JJ Orthodontics, DC Orthodontics and d-tech Orthodontics) showed mean difference between intercanine width for $G$ and $\mathrm{H}$ ortho arch wires was $0.26 \pm 0.25$,for d-tech it was $1.28 \pm 0.31$, for JJ Orthodontics it was $1.28 \pm 0.31$ and for DC Orthodontics it was 1.77 \pm 0.29 . By using one-way ANOVA statistically significant variation was found in intercanine width among four different brands of arch wires (Table 1). 


\section{Table 1: Comparison Of Intercanine Width In Four Different Brands Of Archwires}

\begin{tabular}{|c|c|c|c|c|c|c|c|c|c|c|}
\hline \multirow[t]{2}{*}{ Arch Wires } & \multirow{2}{*}{$\mathrm{N}$} & \multirow{2}{*}{ Mean } & \multirow{2}{*}{$\begin{array}{c}\text { Std. } \\
\text { Deviation }\end{array}$} & \multirow{2}{*}{$\begin{array}{l}\text { Std. } \\
\text { Error }\end{array}$} & \multicolumn{3}{|c|}{$\begin{array}{l}95 \% \text { Confidence } \\
\text { Interval for Mean }\end{array}$} & \multirow{2}{*}{\multicolumn{2}{|c|}{ Minimum }} & \multirow{2}{*}{ Maximum } \\
\hline & & & & & $\begin{array}{l}\text { Lower } \\
\text { Bound }\end{array}$ & \multicolumn{2}{|c|}{$\begin{array}{l}\text { Upper } \\
\text { Bound }\end{array}$} & & & \\
\hline $\mathrm{G}$ and $\mathrm{H}$ Ortho & 60 & 0.26 & 0.25 & 0.03 & 0.20 & \multicolumn{2}{|c|}{0.33} & \multicolumn{2}{|c|}{0.00} & 0.50 \\
\hline d-tech & 60 & 1.28 & 0.31 & 0.04 & 1.20 & \multicolumn{2}{|c|}{1.36} & \multicolumn{2}{|c|}{1.00} & 2.00 \\
\hline JJ Orthodontics & 60 & 1.28 & 0.31 & 0.04 & 1.20 & \multicolumn{2}{|c|}{1.36} & \multicolumn{2}{|c|}{1.00} & 2.00 \\
\hline DC Orthodontics & 60 & 1.77 & 0.29 & 0.03 & 1.69 & \multicolumn{2}{|c|}{1.85} & 1.0 & & 2.00 \\
\hline \multicolumn{11}{|c|}{ One-way ANOVA } \\
\hline Source of variation & \multicolumn{3}{|c|}{ Sum of Squares } & df & \multicolumn{2}{|c|}{ Mean Square } & \multicolumn{2}{|c|}{$\mathrm{F}$} & \multicolumn{2}{|r|}{ p-value } \\
\hline Between Groups & & \multicolumn{2}{|c|}{72.38} & 3 & \multicolumn{2}{|c|}{24.12} & \multirow{3}{*}{\multicolumn{2}{|c|}{280.340}} & \multirow{3}{*}{\multicolumn{2}{|c|}{$0.0001, \mathrm{~S}$}} \\
\hline Within Groups & & \multicolumn{2}{|c|}{20.31} & 236 & \multicolumn{2}{|c|}{0.08} & & & & \\
\hline Total & & \multicolumn{2}{|c|}{92.69} & 239 & & & & & & \\
\hline
\end{tabular}

On comparing intercanine width for all four different types of arch wires statistically significant difference was found between $\mathrm{G}$ and $\mathrm{H}$ ortho and $\mathrm{d}$ tech $(p=0.0001)$, between $G$ and $H$ ortho and $J J$ Orthodontics $(p=0.0001), G$ and $\mathrm{H}$ ortho and DC orthodontics $\quad(p=0.0001), d$-tech and DC orthodontics $\quad(p=0.0001)$ and between JJ orthodontics and DC orthodontics $(\mathrm{p}=0.0001)$ and no significant difference was found between d-tech and JJ orthodontics $(\mathrm{p}=1.00)$. (Table 2$)$.

Comparison of intercanine width in four different brands of arch wires is illustrated in Graph 1.

The comparison intermolar width showed mean intermolar width for $\mathrm{G}$ and $\mathrm{H}$ ortho arch wires was $0.86 \pm 0.41$, for $\mathrm{d}$-tech it was $1.03 \pm 0.46$, for $\mathrm{JJ}$ Orthodontics it was $1.07 \pm 0.46$ and for DC Orthodontics it was $2.07 \pm 0.25$. By using one-way ANOVA statistically significant variation was found in intermolar width among four different brands of arch wires $(\mathrm{F}=107.56, \mathrm{p}$-value $=0.0001)$ (Table 3).
Table 4 shows that on comparing intermolar width for all four different types of arch wires statistically significant difference was found between $\mathrm{G}$ and $\mathrm{H}$ ortho and JJ Orthodontics ( $\mathrm{p}=0.030), \mathrm{G}$ and $\mathrm{H}$ ortho and DC orthodontics $(p=0.0001)$, d-tech and DC orthodontics $(p=0.0001)$ and between JJ orthodontics and DC orthodontics $(p=0.0001)$ and no significant difference was found between d-tech and JJ orthodontics $(\mathrm{p}=0.945)$ and between $\mathrm{G}$ and $\mathrm{H}$ ortho and d-tech $(\mathrm{p}=0.119)$.

Comparison of intermolar width in four different brands of arch wires is illustrated in Graph 2.

\section{DISCUSSION}

Ethnicity is an important factor that influences the shape and dimension of dental arches. Different ethnic populations have various dental arch dimensions. Our available preformed orthodontic arch wires are designed and fabricated in other countries based on the mean of arch size and shape 


\begin{tabular}{|c|c|c|c|c|c|c|}
\hline \multirow{2}{*}{\multicolumn{2}{|c|}{ Arch wires }} & \multirow{2}{*}{$\begin{array}{c}\text { Mean } \\
\text { Difference } \\
(\mathrm{I}-\mathrm{J})\end{array}$} & \multirow{2}{*}{ Std. Error } & \multirow{2}{*}{$\mathrm{p}$-value } & \multicolumn{2}{|c|}{$\begin{array}{l}\text { 95\% Confidence } \\
\text { Interval }\end{array}$} \\
\hline & & & & & $\begin{array}{l}\text { Lower } \\
\text { Bound }\end{array}$ & $\begin{array}{l}\text { Upper } \\
\text { Bound }\end{array}$ \\
\hline \multirow{3}{*}{ G and H Ortho } & d-tech & -1.01 & 0.05 & $0.0001, \mathrm{~S}$ & -1.15 & -0.87 \\
\hline & JJ Orthodontics & -1.01 & 0.05 & $0.0001, \mathrm{~S}$ & -1.15 & -0.87 \\
\hline & DC Orthodontics & -1.50 & 0.05 & $0.0001, \mathrm{~S}$ & -1.64 & -1.36 \\
\hline \multirow{2}{*}{ d-tech } & JJ Orthodontics & 0.00 & 0.05 & $1.000, \mathrm{NS}$ & -0.13 & 0.13 \\
\hline & DC Orthodontics & -0.49 & 0.05 & $0.0001, \mathrm{~S}$ & -0.63 & -0.35 \\
\hline JJ Orthodontics & DC Orthodontics & -0.49 & 0.05 & $0.0001, \mathrm{~S}$ & -0.63 & -0.35 \\
\hline
\end{tabular}

\section{Graph 1: Comparison of Intercanine Width in Four Different Brands of Archwires}

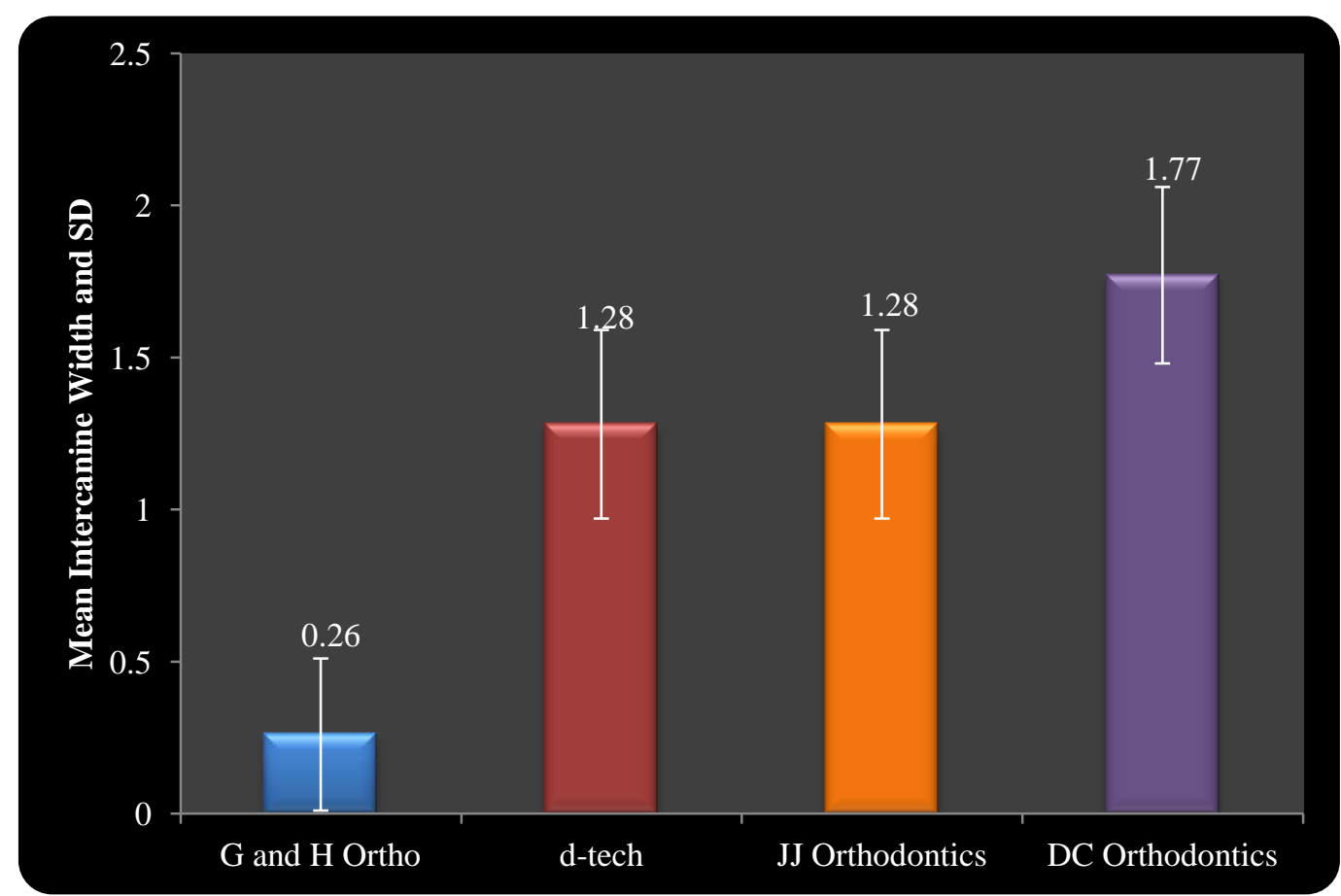


Table 3: Comparison of Intermolar Width in Four Different Brands of Archwires

\begin{tabular}{|c|c|c|c|c|c|c|c|c|c|}
\hline \multirow[t]{2}{*}{ Arch Wires } & \multirow{2}{*}{$\mathrm{N}$} & \multirow{2}{*}{ Mean } & \multirow{2}{*}{$\begin{array}{c}\text { Std. } \\
\text { Deviation }\end{array}$} & \multirow{2}{*}{$\begin{array}{l}\text { Std. } \\
\text { Error }\end{array}$} & \multicolumn{3}{|c|}{$\begin{array}{l}95 \% \text { Confidence } \\
\text { Interval for Mean }\end{array}$} & \multirow{2}{*}{ Minimum } & \multirow{2}{*}{ Maximum } \\
\hline & & & & & $\begin{array}{l}\text { Lower } \\
\text { Bound }\end{array}$ & \multicolumn{2}{|c|}{$\begin{array}{l}\text { Upper } \\
\text { Bound }\end{array}$} & & \\
\hline $\mathrm{G}$ and $\mathrm{H}$ Ortho & 60 & 0.86 & 0.41 & 0.05 & 0.76 & \multicolumn{2}{|c|}{0.97} & 0.00 & 1.50 \\
\hline d-tech & 60 & 1.03 & 0.46 & 0.06 & 0.91 & \multicolumn{2}{|c|}{1.15} & 0.5 & 2.00 \\
\hline JJ Orthodontics & 60 & 1.07 & 0.46 & 0.06 & 0.95 & \multicolumn{2}{|c|}{1.19} & 0.5 & 2.00 \\
\hline DC Orthodontics & 60 & 2.07 & 0.25 & 0.03 & 2.00 & \multicolumn{2}{|c|}{2.14} & 1. & 2.50 \\
\hline \multicolumn{10}{|c|}{ One-way ANOVA } \\
\hline Source of variation & \multicolumn{3}{|c|}{ Sum of Squares } & df & \multicolumn{2}{|c|}{ Mean Square } & \multicolumn{2}{|c|}{$\mathrm{F}$} & p-value \\
\hline Between Groups & & \multicolumn{2}{|c|}{54.27} & 3 & \multicolumn{2}{|c|}{18.09} & \multirow{3}{*}{\multicolumn{2}{|c|}{107.56}} & \multirow{3}{*}{$0.0001, \mathrm{~S}$} \\
\hline Within Groups & & \multicolumn{2}{|c|}{39.69} & 236 & \multicolumn{2}{|c|}{0.16} & & & \\
\hline Total & & \multicolumn{2}{|c|}{93.96} & 239 & & & & & \\
\hline
\end{tabular}

Table 4: Comparison of Intermolar Width Between Four Different Brands of Archwires

\begin{tabular}{|c|c|c|c|c|c|c|}
\hline \multirow{2}{*}{\multicolumn{2}{|c|}{ Arch wires }} & \multirow{3}{*}{$\begin{array}{c}\text { Mean } \\
\text { Difference } \\
(\mathrm{I}-\mathrm{J})\end{array}$} & \multirow{3}{*}{$\begin{array}{c}\text { Std. Error } \\
0.07\end{array}$} & \multirow{3}{*}{$\begin{array}{c}\text { p-value } \\
0.119, \text { NS }\end{array}$} & \multicolumn{2}{|c|}{$95 \%$ Confidence Interval } \\
\hline & & & & & $\begin{array}{l}\text { Lower } \\
\text { Bound }\end{array}$ & $\begin{array}{l}\text { Upper } \\
\text { Bound }\end{array}$ \\
\hline \multirow{3}{*}{ G and H Ortho } & d-tech & & & & -0.36 & 0.02 \\
\hline & JJ Orthodontics & -0.20 & 0.07 & $0.030, \mathrm{~S}$ & -0.40 & -0.01 \\
\hline & DC Orthodontics & $-1.20^{*}$ & 0.07 & $0.0001, \mathrm{~S}$ & -1.40 & -1.01 \\
\hline \multirow{2}{*}{ d-tech } & JJ Orthodontics & -0.04 & 0.07 & $0.945, \mathrm{NS}$ & -0.23 & 0.15 \\
\hline & DC Orthodontics & $-1.04^{*}$ & 0.07 & $0.0001, \mathrm{~S}$ & -1.23 & -0.84 \\
\hline JJ Orthodontics & DC Orthodontics & $-1.00^{*}$ & 0.07 & $0.0001, \mathrm{~S}$ & -1.19 & -0.80 \\
\hline
\end{tabular}




\section{Graph 2: Comparison of Intermolar Width in Four Different Brands of Archwires}

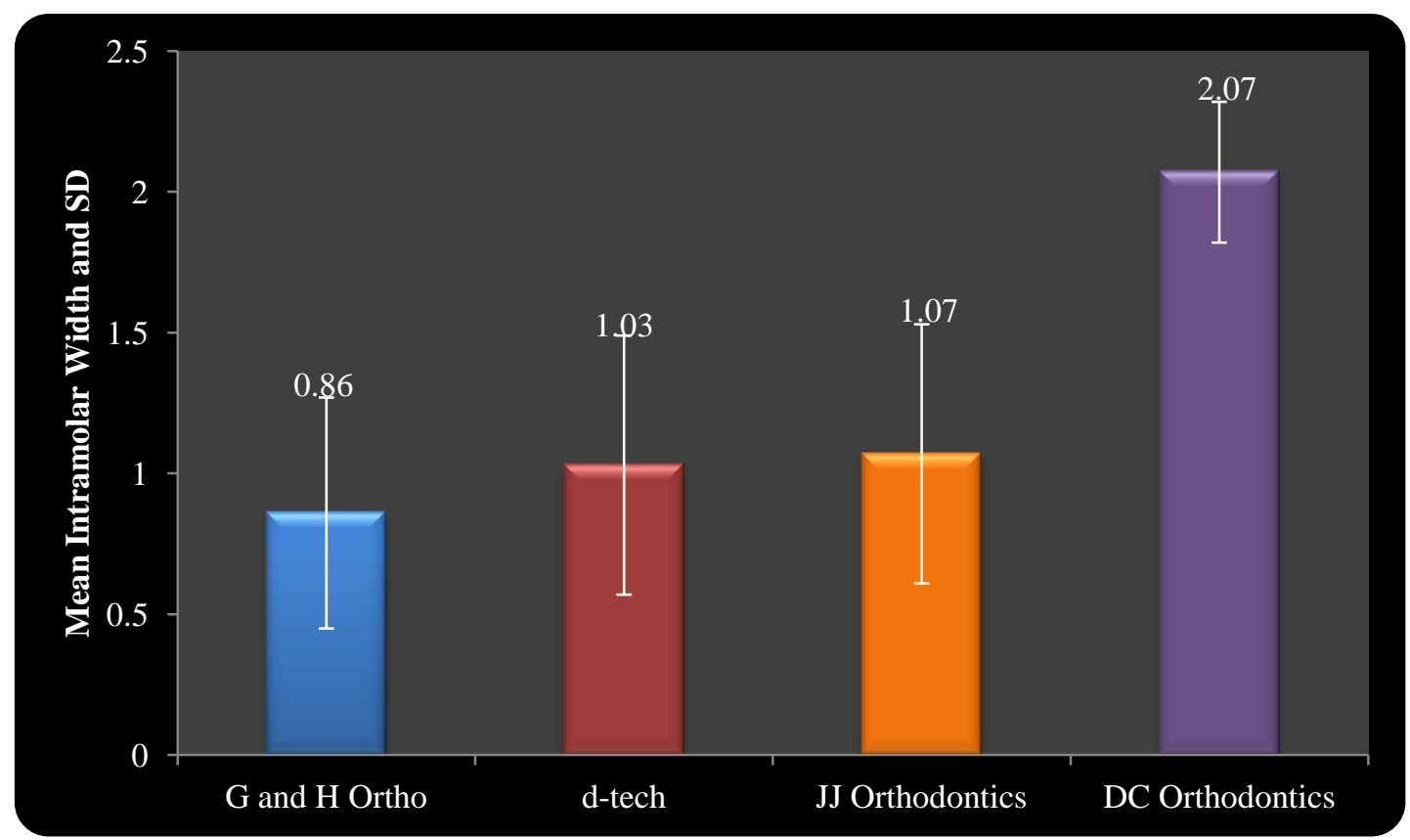

of the manufacturers' own population. Therefore, it is necessary to compare dental arch dimensions of our population with those of commercially available arch wires for selecting more appropriate arch wires. Moreover, this will reduce the risk of post orthodontic occlusal relapse and lead into longer post treatment retention and more stability. Some previous studies have indicated that the relapse potential is related to orthodontic changes in dental arch dimensions, particularly in the lower intercanine area., ${ }^{9,10}$ Therefore, maintaining the mandibular intercanine width during treatment leads to more stable orthodontic results. That was why the mandibular arch was selected for the current study.

In this study there is significant difference between the intercanine and the intermolar widths obtained from that of the arch forms of patients and that of the commonly used archwires of four different companies i.e. G \& H orthodontics, JJ orthodontics, DC orthodontics and d-tech orthodontics. The least Difference between the intercanine $(0.26 \pm 0.25$ $\mathrm{mm})$ and the intermolar width $(0.86 \pm 0.41)$ of archform obtained and the archwire used was found with $\mathrm{G}$ and $\mathrm{H}$ Orthodontics archwires. More difference between the intercanine $(1.77 \pm 0.29 \mathrm{~mm})$ and intermolar $(2.07 \pm 0.25 \mathrm{~mm})$ width of archform and archwire was found between DC orthodontics archwires.

A study conducted by Bhowmik et $\mathrm{al}^{11}$ showed that the preformed rectangular $\mathrm{NiTi}$ archwires were wider in intercanine and intermolar widths than the average dental arches of both the sexes. These studies have only used the mean of Intercanine and intermolar width for selecting the most appropriate arch wires. ${ }^{7,11}$ Finding arch wires that match most dental arches would be a more valuable method than considering the mean for choosing the appropriate arch wires.

There are different arch forms in every population. In a study by Bayome et al. ${ }^{12}$ dividing dental arches into five arch forms instead of three arch forms produced no clinically significant differences. Hence, the classification based on three major arch forms seems more advantageous for clinical applications. The most frequent arch shape and average arch size of different ethnicities must be considered when selecting arch wires because each 
company manufactures arch wires according to the normal dental arch size and shape of a special population. In average Indian population about $50 \%$ of arch form is ovoid, $27 \%$ tapered and $23 \%$ square is observed. ${ }^{13}$ Therefore this study only included mandibular dental casts of ovoid arch form. In spite of the availability of various brands of arch wires in Iran, only a few of them can be used safely to avoid post treatment instability. These facts suggest that manual arch wire adjustments may be necessary for prevention of side effects of stainless steel arch wires with inappropriate width. further studies are required to compare preformed arch wires with patients with skeletal Class II or Class III. Also, extraction cases with severe crowding may need special preformed nickel-titanium arch wires due to their smaller arches.

\section{CONCLUSION}

From this study, following things can be concluded:

1. Archwires from $\mathrm{G}$ and $\mathrm{H}$ orthodontics (Euro form

I) were most suitable for the archform observed in Indian population.

2. Most of the preformed arch wires were wider in both intercanine and intermolar width than the average widths of our population dental arch.

3. The variation in available preformed arch wires does not entirely cover the range of diversity of the normal dental arch.

Financial support and sponsorship: Nil.

Conflicts of interest: There are no conflicts of interest.

\section{REFERENCES}

1. Hedayati Z, Fakhri F, Moshkel Gosha V. Comparison of commercially available arch wires with normal dental arch in a group of Iranian population. J Dent. 2015;16(2):106-10612.

2. Kook YA, Nojima K, Moon HB, McLaughlin
RP, Sinclair PM. Comparison of arch forms between Korean and North American white populations. Am J Orthod Dentofac Orthop. 2004;126(6):680-6.

3. Taner $\mathrm{T}$, Ciğer S, El H, Germeç D, Es A. Evaluation of dental arch width and form changes after orthodontic treatment and retention with a new computerized method. Am J Orthod Dentofac Orthop. 2004;126(4):463-74.

4. Gupta S, Ratre RK, Jain S, Chandki R. Simple way of recording dental arch forms. J Clin Diagnostic Res. 2015;9(3):ZM04-5.

5. Arumugam M, Baskaranarayanan B, Babu D. Comparison of Dental arch widths, arch forms in different types of malocclusions in Chennai population-a 3D laser scanner study. RGUHS Journal of Medical Sciences. 2015;5(3):66-73.

6. Othman SA, Xinwei ES, Lim SY, Jamaludin M, Mohamed NH, Yusof ZYM, et al. Comparison of arch form between ethnic malays and Malaysian aborigines in peninsular Malaysia. Korean J Orthod. 2012;42(1):47-54.

7. Oda S, Arai K, Nakahara R. Commercially available archwire forms compared with normal dental arch forms in a Japanese population. Am $\mathbf{J}$ Orthod Dentofac Orthop. 2010;137(4):520-7.

8. Braun S, Hnat WP, Leschinsky R, Legan HL. An evaluation of the shape of some popular nickel titanium alloy preformed arch wires. Am J Orthod Dentofacial Orthop. 1999;116(1):1-12.

9. Raberin M. in Subjects. Am J Orthod Dentofac Orthop. 1993;265.

10. De la Cruz A, Sampson P, Little RM, Årtun J, Shapiro PA. Long-term changes in arch form after orthodontic treatment and retention. Am J Orthod Dentofac Orthop. 1995;107(5):518-30.

11. Bhowmik SG, Hazare PV, Bhowmik $\mathrm{H}$. Correlation of the arch forms of male and female 
subjects with those of preformed rectangular nickeltitanium archwires. Am J Orthod Dentofac Orthop 2012;142(3):364-73.

12. Park KH, Bayome M, Park JH, Lee JW, Baek $\mathrm{SH}$, Kook YA. New classification of lingual arch form in normal occlusion using three dimensional virtual models. Korean J Orthod. 2014;45(2):74-81.

13. Maniklal Khatri J, Madaan JB. Evaluation of Arch Form among Patients Seeking Orthodontic Treatment. J Indian Orthod Soc. 2012;46:325-8. 